\title{
PROSES PENGUKURAN PEMBUATAN BAJU BERBASIS ANDROID
}

\author{
Yois Balian Ilyasa ${ }^{1}$, Miftachul Ulum² $^{2}$ Achmad Fiqhi Ibadillah ${ }^{3}$ \\ ${ }^{1,2,3} \mathrm{~S} 1$ Teknik Elektro, Fakultas Teknik, Universitas Trunojoyo Madura \\ yosspit@gmail.com \\ miftachul.ulum@trunojoyo.ac.id \\ fiqhi.ibadillah@trunojoyo.ac.id
}

\begin{abstract}
Abstrak - Sudah banyak bermacam macam ukuran yang tersedia di pasaran. Namun sudah banyak juga orang yang lebih memilih membuat bajunya sendiri. Karena kebanyakan ukuran tiap orang berbeda-beda ataupun memang untuk kebutuhan kerja dan lainnya. Untuk mempermudah penjahit, bidang ilmu teknologi dan ilmu komunikasi memberikan kemudahan dengan menggunakan pengolahan citra untuk mengetahui ukuran badan seseorang yang meliputi (panjang lengan, tinggi baju, dan lingkar dada). Penelitian ini menggunakan rancang bangun proses pengukuran pembuatan baju yang berbasis android, yang akan memudahkan penjahit untuk mengukur setiap pelanggan tampa harus bertatap muka yang pastinya dengan waktu yang singkat dan efisien. Pada proses pengukuran menggunakan Image Processing dengan metode Haar Casecade dikombinasikan dengan data yang sebelumnya sudah di ketahui oleh penjahit. Pada penelitian ini menggunakan data acuan standart ukuran kemeja pria. Data acuan di gunakan untuk perbandingan ukuran antara panjang lengan, lebar dada, dan tinggi badan. Dari hasil penelitian menghasilkan rata-rata eror pada setiap parameter yaitu panjang lengan $8 \%$, lebar dada 5\%, dan tinggi badan 3\%. Untuk akurasi pada setiap pengkuran paling tinggi adalah pada tinggi badan yaitu $97 \%$.
\end{abstract}

Kata Kunci: image processing, haar casecade, pengukuran baju, android

\begin{abstract}
There are many different kinds of sizes available in the market. But there are many people who prefer to make their own clothes. Because most of the size of each person is different or indeed for work and other needs. To facilitate the tailors, the field of technology and communication science makes it easy to use image processing to determine the size of a person's body which includes (arm length, dress height, and chest circumference). This study uses the design of the process of measuring clothes making based on Android, which will make it easier for tailors to measure every customer without having to face-to-face, which certainly is short and efficient. In process of measuring using Image Processing with the Haar Casecode method combined with data previously known by the tailor. In this study using standard reference data on men's shirt sizes. Reference data are used for comparison of measurements between arm length, chest width and height. The results of the study resulted in an average error in each parameter, namely $8 \%$ arm length, $5 \%$ chest width, and $3 \%$ height. For accuracy at each measurement the highest is at body height which is $97 \%$.
\end{abstract}

Keywords: image processing, haar casecade, clothing size measurement, android

\section{PENDAHULUAN}

Pakaian adalah kebutuhan pokok manusia selain makanan dan tempat tinggal (rumah). Manusia membutuhkan pakaian untuk melindungi dan menutup dirinya. Begitu juga dengan ukuran baju yang di kenakan. Sudah banyak bermacam macam ukuran yang tersedia di pasaran. Namun sudah banyak juga orang yang lebih memilih membuat bajunya sendiri. Karena kebanyakan ukuran tiap orang berbeda-beda ataupun memang menyesuaikan kebutuhan. Namun kebanyakan masih manual dan membutuhkan waktu untuk mengukur tiap bagian pada tubuh konsumen yang akan di buatkan bajunya [1].

Pada prosesnya Image Processing ini berfungsi sebagai proses gambar pada badan seseorang untuk mengidentifikasi ukuran baju orang tersebut dengan citra badan yang telah di ambil menggunakan android dengan jarak yang telah ditentukan sebelumnya [2]. Penjahit hanya perlu input gambar kemudian sintem akan memproses citra yang meliputi ukuran lingkar dada, panjang lengan, dan panjang baju. Pada penelitian ini, akan dirancang sebuah aplikasi yang akan memudahkan pada saat perngukuran baju. Sistem yang di rancang adalah sistem aplikasi otomatis, menggunakan metode Haar Case Cade. Pada sistem aplikasi terdapat empat tahapan, berikut: (1) pemesanan, (2) input Citra, (3) proses pengukuran baju, dan (4) output ukuran baju. 


\section{METODE}

Pada penelitian ini, perancanmgan dan pengembangan perangkat lunak yang mengacu pada pembuatan aplikasi yeng terdiri dari: analisa kebutuhan sustem (system requirement), desain sistem (design), implementasi sistem (implementation), dan pengujian sistem (testing).

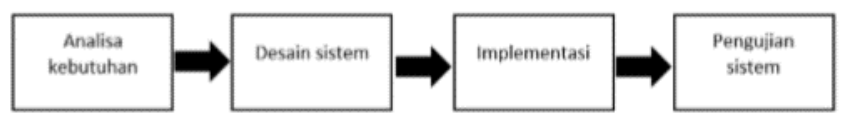

Gambar 1. Tahapan Metodologi Penelitian

Deskripsi tiap tahapan berdasarkan gambar 1 sebagai berikut:

\section{Analisa Kebutuhan Sistem}

Pada tahap ini di lakukan analisa kebutuhan sistem berdasarkan data yang di ambil secara langsung. Langkah awal yang dilakukan pada tahapan ini adalah mengukur secara manual ukuran baju pada setiap individu untuk di buat perbandingan antara ukuran asli dan ukuran pada aplikasi. Salah satu acuan dari penelitian ini adalah ukuran baju kemeja pria [3].

Hasil dari tahapan ini adalah data pribadi individu, input gambar obyek, yang kemudian akan di proses pada tahapan selanjutnya.

\section{Desain Sistem}

Berdasarkan data pada tahapan analisa kebutuhan sistem kemudian di buat desain sistem. Desain sistem yang di buat antara lain: desain tampilan menu utama, desain tampilan data diri, desain proses (output), dan desain data tersimpan.

Dalam pembuatan desain sistem, peneliti menggunakan alat bantu yakni tripot agar pada saat pengambilan gambar kamera bisa stabil. Pada desan tampilan menu utama akan di tampilkan layout yang berisi pesan dan file yang tersimpan. Untuk menu pesan nantinya akan di arahkan pada menu pengisian data di seperti nama, kain yang di pilih, nomor telepon. Sedangkan untuk file tersimpan adalah file hasil pengukuran sebelumnya.

Pada desain pengisian data di adalah proses pengambilan gambar yang akan nantinya akan di proses untuk di hutung berapa ukuran bajunya.

\section{Implementasi Sistem}

Pada tahap ini dilakukan alur pengolahan dari citra manusia (obyek) hingga di peroleh ukuran baju. Penelitian ini menggunakan open cv, open cv di gunakan untuk mendeteksi obyek dengan muka sebagai acuan[4], Kemudian akan muncul kotak hijau sebagai yang selanjutnya citra akan di hitung. Perhitungan menggunakan metode Haar Casecade, dimana metode ini menandai obyek atau citra yang akan di hitung ukuran pixel hanya pada citra yang di dalam kotak hijau [5]. Dalam proses ini di gunakan konversi pixel yaitu mengubah pixel ke centimeter $(\mathrm{cm})$ atau menjadi ukuran sebenarnya [6]. Setelah di konversi dan di proses kemudian citra akan di hitung ukuran baju kemudian di peroleh hasil ukuran baju yang akan di tampilkan pada layout aplikasi.

\section{Pengujian Sistem}

Pada tahap ini dilakukan pengujian perangkat lunak yaitu hanya untuk ukuran baju laki-laki dengan menguji berapa jarak pengambilan dengan perbandingan antara ukuran baju asli dengan ukurang pada perangkat lunak [7]. jika masih terdapat error akan di lakukan perbaikan. Dari tahapan ini di harapkan perangkat lunak dapat menghitung secara tepat sehingga dapat di gunakan pada proses pengukuran baju yang sebenarnya.

\section{Subjek Penelitian}

Subyek penelitian ini adalah 50 individu dengan ukuran baju berbeda-beda yang meliputi: (1) 30 mahasiswa laki-laki jurusan teknik elektro, (2) 30 orang yang di ambil secara acak.

\section{Teknologi yang digunakan}

Teknologi yang di gunakan dalam pembuatan perangkat lunak ini berbasis android. Teknologi yang di gunakan dalam penelitian ini antara lain: (1) bahasa pemrograman java, (2) menggunakan Open cv untuk deteksi obyek manusia, (3) watsup untuk pengiriman data jarak jauh.

Alasan pembuatan aplikasi pada penelitian ini adalah agar lebih fleksibel dan mempermudah orang yang tidak memiliki pengetahuan mengukur baju secara manual.

\section{HASIL DAN PEMBAHASAN}

Hasil dan pembahasan penelitian ini menyajikan data meliputi proses pengambilan citra pada obyek manusia, metode perhitungan, dan hasil dari perhitungan aplikasi pengukur baju menggunakan android.

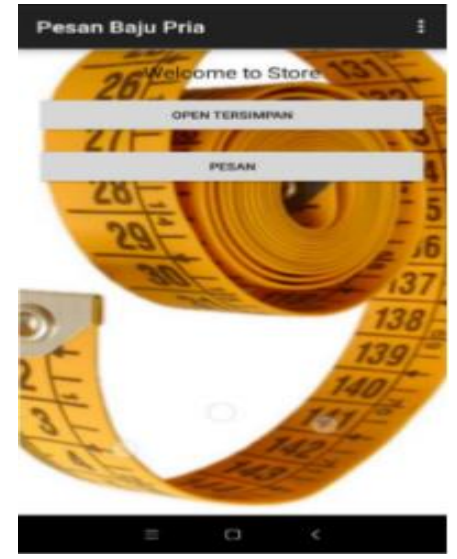

Gambar 2. Halaman Utama Aplikasi 
Pada uji coba sistem ini mengikuti ukuran standart baju untuk kemeja pria sebagai acuan. Pengambilan gambar di lakukan hanya pada sisi depan. Pengujian ini bertujuan untuk mengetahui apakah aplikasi yang di bangun berjalan sesuai yang di inginkan atau tidak, sehingga nantinya dapat di analisa lebih lanjut.

\section{Penentuan Jarak}

Pengujian dilakukan dengan tiga metode pengambilan yaitu pengambilan obyek dengan jarak 1 meter, 1.5 meter, dan 2 meter dengan pencahayaan yang cukup dengan ukuran asli panjang lengan $23 \mathrm{~cm}$, lebar dada $47 \mathrm{~cm}$ dan tinggi baju $66 \mathrm{~cm}$.

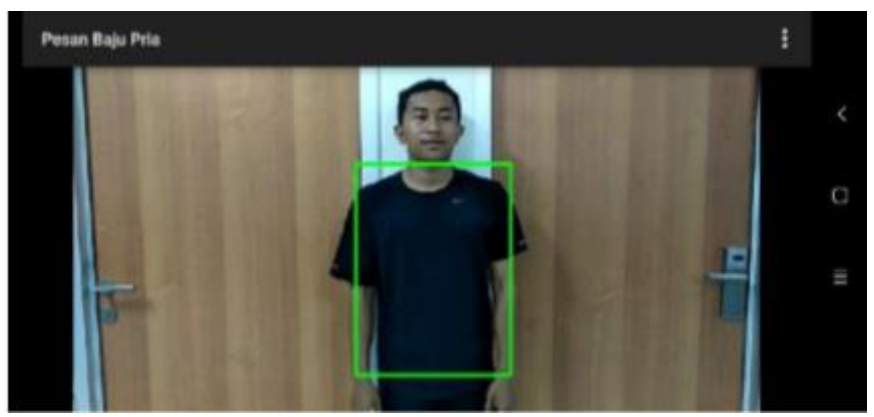

Gambar 3. Pengembilan Gambar pada Aplikasi

Gambar 3 merupakan proses pengambilan citra obyek dengan menggunakan aplikasi pengukur baju. Aplikasi ini mendeteksi tinggi badan berdasarkan ukuran pixel yang telah di terima [8]. Kemudian gambar akan di proses dan akan di dapatkan hasil pengukuran seperti pada gambar 4 di bawah ini:

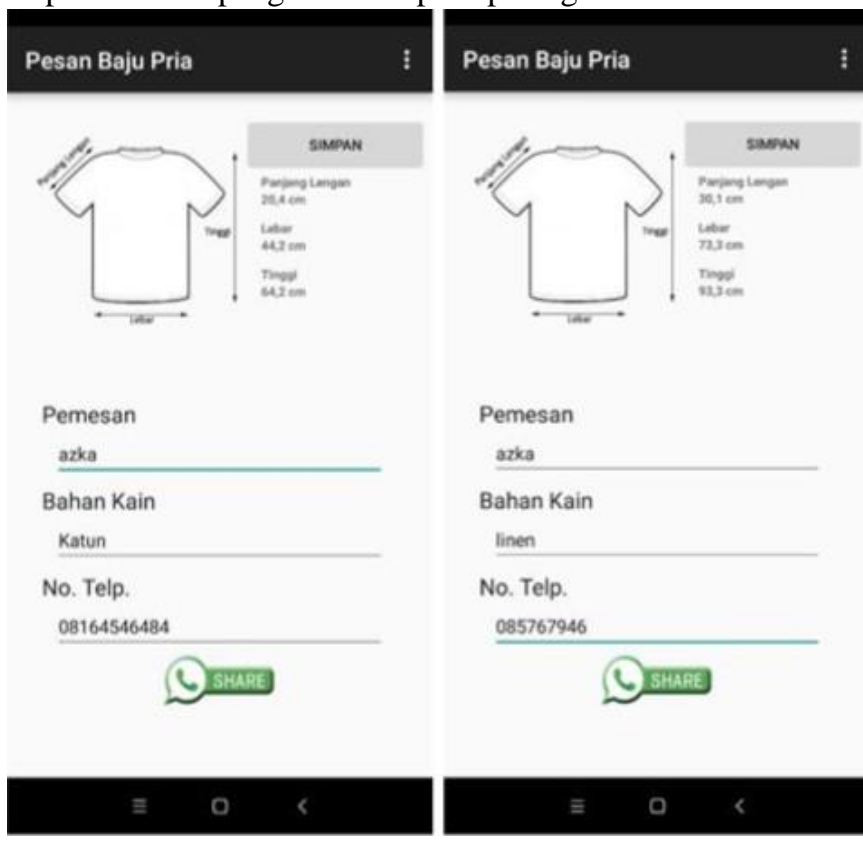

Gambar 4. Output Aplikasi

Gambar (1) adalah jarak 1,5 meter. Gambar (2) adalah jarak 1 meter. Dari hasil pengukuran dengan jarak 1.5 meter pada aplikasi pengukur baju maka di dapat ukuran panjang lengan
$20.4 \mathrm{~cm}$, lebar dada $44.2 \mathrm{~cm}$ dan tinggi baju $64.2 \mathrm{~cm}$. Untuk pengukuran pada aplikasi pada jarak 1 meter di dapat ukuran panjang lengan $30.1 \mathrm{~cm}$. Lebar dada $73.3 \mathrm{~cm}$ dan tinggi 93.3 $\mathrm{cm}$.

Tabel 1. Pengujian Jarak

\begin{tabular}{cccccc}
\hline Jarak & Ukuran & $\begin{array}{c}\text { Ukuran } \\
\text { asli }\end{array}$ & $\begin{array}{c}\text { Ukuran } \\
\text { aplikasi }\end{array}$ & Selisih & Error\% \\
\hline \multirow{2}{*}{$\begin{array}{c}1 \\
\text { meter }\end{array}$} & PL & 23 & 30.1 & 7.1 & $30.8 \%$ \\
\cline { 2 - 6 } & LD & 47 & 73.3 & 26.3 & $55.9 \%$ \\
\cline { 2 - 6 } & TB & 66 & 93.3 & 27.3 & $41.3 \%$ \\
\hline \multirow{2}{*}{$\begin{array}{c}1.5 \\
\text { meter }\end{array}$} & PL & 23 & 20.4 & 2.6 & $11.3 \%$ \\
\cline { 2 - 6 } & LD & 47 & 44.2 & 2.8 & $5.9 \%$ \\
\cline { 2 - 6 } & TB & 66 & 64.2 & 1.8 & $2.7 \%$ \\
\hline \multirow{2}{*}{$\begin{array}{c}2 \\
\text { meter }\end{array}$} & PL & 23 & - & - & - \\
\cline { 2 - 6 } & LD & 47 & - & - & - \\
\cline { 2 - 6 } & TB & 66 & - & - & - \\
\hline
\end{tabular}

Tabel 1 adalah percobaan pengujian jarak dengan menggunakan aplikasi android di peroleh hasil, apabila pengambilan dengan jarak 1 meter memiki error pada panjang lengan (PL) 30.8\%, lebar dada (LD) 55.9\%, dan tinggi badan (TB) $41.3 \%$. pada jarak 1.5 meter memiliki error pada panjang lengan (PL) $11.3 \%$, lebar dada (LD) $5.9 \%$, dan tinggi badan (TB) $2.7 \%$. Pada jarak 2 meter pengambilan gambar tidak dapat di lakukan di karnakan aplikasi tidak bisa mendeteksi ukuran badan obyek. Jika jarak terlalu jauh maka obyek tidak dapat terdeteksi oleh sistem dengan baik [9]. Maka jarak yang paling efektif untuk pengambilan data ukuran baju pada jarak 1.5 meter.

\section{Pengujian Aplikasi}

Dalam pengujian ini berasal dari citra 50 individu yang di ambil secara acak dengan ukuran badan yang berbeda-beda. Pengambilan dilakukan dengan jarak 1.5 meter dan dengan pencahayaan yang cukup. Pengujian ini di ambil berdasarkan ukuran standar kemeja pria. Hasil pengukuran meliputi panjang lengan, lebar dada, dan tinggi badan. Adapun untuk menghitung Error dan Akurasi pada aplikasi munggunakan rumus sebagai berikut:

Rumus hitung Error

$$
\text { Error }(\%)=\frac{\text { Rata }- \text { rata selisih }}{\text { Rata-rata ukuran baju }} \times 100 \%
$$

Rumus hitung Akurasi

$$
\text { Akurasi }=100 \%-\text { Error }
$$

Tabel 2. Hasil Pengukuran

\begin{tabular}{ccccc}
\hline Ukuran & $\begin{array}{c}\text { Rata-rata } \\
\text { Ukuran asli }\end{array}$ & $\begin{array}{c}\text { Rata-rata } \\
\text { selisih }\end{array}$ & Error & Akurasi \\
\hline Panjang Lengan & 22.34 & 1.89 & $8 \%$ & $92 \%$ \\
\hline Lebar Dada & 45.58 & 2.54 & $5 \%$ & $95 \%$ \\
\hline Tinggi Badan & 64.96 & 2.19 & $3 \%$ & $97 \%$
\end{tabular}


Dari hasil perhitungan tabel $2 \mathrm{di}$ atas rata-rata akurasi dari 50 individu yang setiap individu menghasilkan tiga sampel data di dapat akurasi panjang lengan 92\%, lebar dada 95\%, dan tinggi badan $97 \%$. Dari akurasi dapat di lihat yang paling mendekati adalah pada ukuran panjang badan. Untuk ukuran lebar dada pada ujicoba kurang presisi di karenakan ukuran lebar dada setiap individu berbeda-beda dan pencahayaan yang kurang maksimal.

\section{PENUTUP}

\section{Simpulan}

Pada penenlitian byang telah di lakukan, Haar Casecade merupakan metode yang umum di gunakan untuk mendeteksi sebuah obyek. Metode ini memiliki kelebihan yaitu komputasinya sangat cepat, karena hanya bergantung pada jumlah pixel dalam persegi bukan setiap nilai piksel dari sebuah image. Pada pengujian aplikasi hal yang paling penting yang harus di perhatikan adalah faktor cahaya. Hasil yang terkadang kurang pas di sebabkan oleh cahaya yang agak kurang di karenakan pengujian di lakukan di tempat yang berbedabeda.Jarak paling ideal untuk pengambiulan gambar pada aplikasi pengukur baju yaitu pada jarak $150 \mathrm{~cm}$, karena jarak pengambilan gambar mempengaruhi perbandingan ukuran objek dan ukuran sebenarnya. Berdasarkan percobaan yang telah di lakukan, aplikasi dapat menghitung ukuran baju obyek dengan persentase keakuratan panjang lengan 92\%, lebar dada $95 \%$, dan pangjang badan $97 \%$.

\section{Saran}

Saran untuk pengembangan aplikasi ini adalah Aplikasi ini dapat di kembangkan menjadi aplikasi yang lebih komplek dan akurat. Aplikasi ini dapat dikembangan dengan output bagian tubuh yang lebih banyak. Yang nantinya agar tidak hanya untuk mengukur pria saja tapi juga wanita.

\section{DAFTAR PUSTAKA}

[1] Nazori, Awaludin, "Prototype ukuran baju dengan teknik pengolahan citra digital," Jurnal ilmu computer, program pancasarjana Universitas Budi Luhur, Vol.6, No.2, 2014.

[2] Arina Fitritul Fajariyah, Riza Alvita, Haryanto, "Aplikasi Penaksir Bobot Sapi Menggunakan Image Processing Berbasis Android," Jurnal Universitas Trunojoyo Madura, 2018.

[3] Erlinda Muslim, Boy Nurtjahyo Moch., Nauli Dwi Fileinti, Maya Arlini Puspasari, Triasni M. L. Sibarani \& DeoG. N. Laksana, "The Development of Standard Size for Clothes of Indonesian Boys Based on Anthropometric Data as a Reference to Formulate RSNI 0555," International Journal of Ergonomics (IJEG), Volume 4, 2014.

[4] Umam Khairul, Negara Benny Sukma, "Deteksi Obyek Manusia Pada Basis Data Video Menggunakan Metode Background Subtraction Dan Operasi Morfologi," Jurnal UIN Sultan Syarif Kasim Riau, Jurnal CoreIT, Vol.2, No.2, 2016.

[5] Sayeed Al-Aidid dan Daniel S. Pamungkas, "Sistem Pengenalan Wajah dengan Algoritma Haar Cascade dan Local Binary Pattern Histogram," Jurnal Rekayasa Elektrika Vol. 14, No. 1, 2018.
[6] Rakhmad Kuswandhiea, Jufriadif Na'amb, Yuhandric, "Pengukuran Tinggi Sebenarnya Objek pada Foto Digital Menggunakan Euclidean Distance," Jurnal Universitas Putra Indonesia Vol. 2, 2018.

[7] Wisnu, Ajhi. Susanto, Adhi. Soesanti, Indah, "Pengukur Baju Via Webcam Dengan Labview," Jurnal Penelitian Teknik Elektro, Vol. 3 No. 4, 2010.

[8] Abolfazl Davodi Roknabadi, Masoud Latifi, Siamak Saharkhiz and Hamed Aboltakhty, "Human Body Measurement System In Clothing Using Image Processing," Jurnal Department of Textile Engineering, Science and Research Branch, Islamic Azad University, Tehran, Iran Department of Textile Engineering, Textile Research and Excellence Centers, Amirkabir University of Technology, Tehran, Iran Young Researchers Club, Science and Research Branch, Islamic Azad University, Tehran, Iran. Vol 19, No. 112-119, 2012.

[9] Wisnu, Ajhi. Susanto, Adhi. Soesanti, Indah, "Pengukur Baju Via Webcam Dengan Labview," Jurnal Penelitian Teknik Elektro, Vol. 3 No. 4,2010 . 